\title{
Control of Gamic and Parthenogenetic Reproduction in Winged Aphids by Temperature and Light ${ }^{1}$
}

\author{
By A. Franklin Shuld \\ University of Michigan, Ann. Arbor, Mich., U.S.A.
}

(Received for publication, 20. August 1929)

That temperature has a strong influence on the inauguration of gamic reproduction in aphids has long been believed. The ground for this belief has been chiefly the fact that gamic forms, in those species which have them at all, appear usually in the fall. Very little evidence from controlled experiments has ever been obtained. Within the last few years there has been a suggestion that the duration of light also influences gamic reproduction, but the experimental evidence of this is likewise slight. The previous work on both temperature and light as agents affecting the mode of reproduction has been reviewed recently (SHULL 1929a), and is therefore not discussed here.

The existence of intermediate aphids, repeatedly mentioned in the literature, indicates that differentiation between parthenogenetic and gamic reproduction may not be a single sharply defined event. It may be either a gradual process or a series of events occurring at different times. An understanding of the precise nature of intermediates might reasonably be sought if the environmental agents producing them were exactly known. With this object in view, the effects of temperature and light have been intensively studied in one aphid, Macrosiphum solanifolii. Since all of the known intermediates relating to the mode of reproduction appear to be those between gamic and parthenogenetic females, and since gamic females are regularly produced by winged mothers, this study has been limited to the effect of temperature and light on reproduction in winged females.

1) Contribution from the Zoological Laboratory of the University of Michigan. 


\section{Crude Contrasts of Temperature}

As a preliminary to more exact experiments, to determine whether the species being used would respond to differences of temperature, numerous trials were made of low and high temperatures crudely obtained. These trials were made in conjunction with wing experiments, hence light conditions were uniform in any one experiment, but differed somewhat from one trial to another. Low temperature was that of a basement room in winter, modified by ventilation from the compressed air system. It was subject to a daily range of about $3^{\circ} \mathrm{C}$., and averaged about $18 \cdot 9^{\circ} \mathrm{C}$. High temperature was obtained by hanging a lighted electric bulb near the chamber in which the aphids were being kept on their plant. Since the aphids were in all cases separated from this lamp by an opaque partition, the degree of illumination was not altered thereby. This high temperature likewise had a daily range of about $3^{\circ}$, and averaged about $24 \cdot 8^{\circ} \mathrm{C}$. Only the parents were reared under the conditions described; their offspring were brought to maturity in ordinary room conditions. The experiment was performed on twelve different occasions, with fairly constant results which, in the aggregate, are shown in table 1. More than one-third of the offspring were parthenogenetic at high temperature only about $1 \%$ parthenogenetic at low temperature.

Table 1. Showing the effect of different temperatures, applied to winged aphids, upon the type of reproduction in their offspring

\begin{tabular}{c|c|c|c|}
\hline At high temperature & Offspring & At low temperature \\
\hline Parthenogenetic & Gamic & Parthenogenetic & Gamic \\
\hline 269 & 513 & 7 & 616 \\
\hline $34.4 \%$ & $1 \%$ &
\end{tabular}

\section{Crude 'Tests of Light}

In the tests of light, only the alternation of 8 hours of light with 16 hours of darkness was compared with continuous light. These periods were maintained with some accuracy; the cradeness of the experiments 
lies chiefly in the fact that the temperature was not ascertained. The temperature was the same in continuous light as in alternate light and darkness, but no attempt was made to keep it constant.

Winged parents were subjected, on 16 different occasions, to the conditions described above, with the results shown in table 2. More than twice as many parthenogenetic females were produced in continuous light as in alternating light and darkness.

Table 2. Showing the offspring of winged aphids reared in continuous light and in alternating light and darkness (8 hours of light daily), with respect to their mode of reproduction

\begin{tabular}{c|c|c|c}
\hline \multicolumn{3}{c}{ Offspring } \\
\hline 8-Hour Light & \multicolumn{2}{c}{ 24-Hour Light } \\
\hline Parthenogenetic & Gamic & Parthenogenetic & Gamic \\
\hline \hline 140 & 988 & $\frac{341}{25 \%}$ & 1005 \\
\hline $12.4 \%$ & & $25 \%$ &
\end{tabular}

\section{Temperature and Light Combined}

Since in the foregoing experiments low temperature and alternating light and darkness appear to favor gamic reproduction, while high temperature and continuous light conduce to parthenogenesis, the two factors were then used in combination, with the expectation that a more marked result would be obtained. A group of young aphids, within 24 hours after birth, presumably destined to be winged because their parents were reared in alternating light and darkness (SHDLl, 1928, $1929 \mathrm{~b}$ ), was divided into two lots, one of which was kept at a temperature of $16^{\circ} \mathrm{C}$. and in alternating light and darkness ( 8 hours and 16 hours, respectively), the other at $24^{\circ}$ and in continuous light. Their offspring were separated into successive groups, each the output of (usually) two days, in order to show any progressive change that might occur. The experiment was performed in January and February, and, as usual at that time of year, stocks of winged females at ordinary room conditions were producing almost exclusively gamic daughters. The results are given in table 3 . 
Control of Gamic and Parthenogenetic Reproduction in Winged Aphids \&c. 111

Table 3. The effect of temperature and light combined upon winged aphids, relative to gamic and parthenogenetic reproduction in their offspring. The conditions named began within 24 hours after the birth of the parents

\begin{tabular}{|c|c|c|c|c|c|}
\hline \multicolumn{3}{|c|}{$16^{0}, 8$-Hour Light } & \multicolumn{3}{|c|}{$24^{\circ}, 24$-Hour Light } \\
\hline \multirow{2}{*}{$\begin{array}{l}\text { Days after } \\
\text { change of } \\
\text { temperature }\end{array}$} & \multicolumn{2}{|c|}{ Offspring } & \multirow{2}{*}{$\begin{array}{l}\text { Days after } \\
\text { change of } \\
\text { temperature }\end{array}$} & \multicolumn{2}{|c|}{ Offspring } \\
\hline & $\begin{array}{l}\text { Partheno- } \\
\text { genetic }\end{array}$ & Gamic & & $\begin{array}{l}\text { Partheno- } \\
\text { genetic }\end{array}$ & Gamic \\
\hline $13-15$ & 3 & 23 & $10-12$ & 19 & 38 \\
\hline $15-17$ & 0 & 30 & $12-15$ & 24 & 19 \\
\hline $17-19$ & 0 & 63 & $15-17$ & 7 & 3 \\
\hline $19-21$ & 0 & 16 & $17-19$ & 8 & 3 \\
\hline $21-23$ & 0 & 28 & $19-21$ & 5 & 4 \\
\hline $23-25$ & 0 & 11 & $21-23$ & 7 & 0 \\
\hline $25-27$ & 0 & 8 & & & \\
\hline $27-38$ & 5 & 10 & & & \\
\hline
\end{tabular}

The offspring produced at low temperature and alternating light and darkness were nearly all gamic, as they presumably would have been under room conditions. The offspring at high temperature and continous light were about one-third parthenogenetic at first, and changed rather steadily until at the end of the experiment all were parthenogenetic. Approximately three weeks of high temperature and continuous light were required to effect a complete transition from gamic to parthenogenetic reproduction in the offspring.

\section{Concurrent and Antagonistic Action of Temperature and Light}

As a preliminary test of the effect of temperature and light acting in the same direction, and of their relative effectiveness when opposed to one another, three lots of winged aphids, all in the fourth instar (last stage before adult), were placed at temperatures of $16^{\circ}, 22^{\circ}$ and $28^{\circ}$, respectively. At each temperature the aphids were divided into two lots one kept in alternating light and darkness (8 hours of light daily), the other in continuous light. Their offspring are recorded in table 4. The difference between alternating and continuous light was negligible at the two lower temperatures, while at $28^{\circ}$ continuons light was distinctly more favorable to parthenogenesis than was alternating light and darkness. Quite in harmony, also, with the preliminary 
test described in an earlier section, the high temperature $\left(28^{\circ}\right)$ was much more conducive to parthenogenesis than was either of the lower temperatures $\left(22^{\circ}\right.$ and $\left.16^{\circ}\right)$.

Table 4. The effect of temperature and light, in cooperation and in opposition, upon gamic and parthenogenetic reproduction in the offspring of winged aphids. The conditions named below began with the fourth instar of the parents

\begin{tabular}{|c|c|c|c|}
\hline \multicolumn{2}{|c|}{$\begin{array}{c}\text { Conditions Under Which } \\
\text { Parents Were Reared }\end{array}$} & \multicolumn{2}{|c|}{ Offspring } \\
\hline $\begin{array}{l}\text { Temperature in } \\
\text { degrees } \mathrm{C} .\end{array}$ & $\begin{array}{l}\text { Light in } \\
\text { hours daily }\end{array}$ & Parthenogenetic & Gamic \\
\hline 16 & 8 & 2 & 33 \\
\hline 16 & 24 & 3 & 46 \\
\hline 22 & 8 & 2 & 18 \\
\hline 22 & 24 & 9 & 79 \\
\hline 28 & 8 & 69 & 23 \\
\hline 28 & 24 & 61 & 1 \\
\hline
\end{tabular}

A more extensive test of the effects of temperature and light in concurrent and antagonistic action is represented in table 5. The winged parents were put under the conditions named in the third or fourth instar in most cases, though a very few had recently become adult at the beginning of the experiment. Eight temperatures were used, representing practically the whole range of constant temperatures which this species will endure. At each temperature some were kept in alternating light and darkness ( 8 and 16 hours, respectively), some in continuous light.

Though the results (table 5) show some irregularity, the significance of them is clear. At temperatures below $22^{\circ}$, very few parthenogenetic danghters were produced except at $16^{\circ}$. The higher percentages at $16^{\circ}$ than at $14^{\circ}, 18^{\circ}$ or $20^{\circ}$ might appear to be significant, as ACKERMAN (1926) concluded they were in relation to wing-production, were it not for a repetition of the test made for the sake of another comparison in table 7 , where the parthenogenetic offspring obtained at $16^{\circ}$ are much less numerous than in table 5 . Above $22^{\circ}$, a large proportion of the offspring were parthenogenetic, this proportion rising to three-fourths or more at $28^{\circ}$. With respect to light, continuous light resulted in more parthenogenetic offspring, at every temperature, than 
Table 5. The effect of temperature and light, applied to winged aphids, upon gamic or parthenogenetic reproduction in their offspring

\begin{tabular}{|c|c|c|c|c|c|c|}
\hline \multirow[b]{2}{*}{$\begin{array}{l}\text { Temperature } \\
\text { in Degrees C. }\end{array}$} & \multicolumn{3}{|c|}{ 8-Hour Light } & \multicolumn{3}{|c|}{ 24-Hour Light } \\
\hline & $\begin{array}{l}\text { Partheno- } \\
\text { genetic }\end{array}$ & Gamic & $\begin{array}{c}\text { Percent } \\
\text { Partheno- } \\
\text { genetic }\end{array}$ & $\begin{array}{l}\text { Partheno- } \\
\text { genetic }\end{array}$ & Gamic & $\begin{array}{c}\text { Percent } \\
\text { Partheno- } \\
\text { genetic }\end{array}$ \\
\hline 14 & 1 & 67 & 1.5 & 4 & 64 & $5 \cdot 9$ \\
\hline 16 & $\begin{array}{r}34 \\
17 \\
4 \\
3 \\
5\end{array}$ & $\begin{array}{l}78 \\
50 \\
81 \\
36 \\
32\end{array}$ & $18 \cdot 5$ & $\begin{array}{r}0 \\
33 \\
3 \\
5 \\
0\end{array}$ & $\begin{array}{l}17 \\
14 \\
39 \\
32 \\
48\end{array}$ & 215 \\
\hline 18 & 2 & 92 & $2 \cdot 1$ & 3 & 97 & $3 \cdot 0$ \\
\hline 20 & 0 & 95 & 00 & 3 & 85 & 34 \\
\hline 22 & $\begin{array}{l}2 \\
0 \\
5\end{array}$ & $\begin{array}{l}83 \\
62 \\
18\end{array}$ & $4 \cdot 1$ & $\begin{array}{r}3 \\
23 \\
9\end{array}$ & $\begin{array}{r}117 \\
52 \\
78\end{array}$ & $12 \cdot 4$ \\
\hline 24 & 5 & 26 & $16 \cdot 1$ & 17 & 20 & $45 \cdot 9$ \\
\hline 26 & 29 & 53 & $35 \cdot 4$ & 47 & 56 & 456 \\
\hline 28 & $\begin{array}{l}15 \\
17 \\
69\end{array}$ & $\begin{array}{r}4 \\
7 \\
23\end{array}$ & $74 \cdot 8$ & $\begin{array}{r}73 \\
7 \\
59\end{array}$ & $\begin{array}{r}19 \\
0 \\
1\end{array}$ & $87 \cdot 4$ \\
\hline
\end{tabular}

did alternating light and darkness. The difference is small at all of the lower temperatures, and it is questionable whether it is significant. It is considerable, however, at temperatures of $22^{\circ}-28^{\circ}$, especially at $24^{\circ}$.

It seems clear that both light and temperature, applied to the winged parents, influence the mode of reproduction of their offspring, but that temperature has a much greater effect than light.

\section{Alternating Temperatures as Contrasted with Constant Temperatures}

Some winged aphids in the fourth instar were divided into three lots, one of which was placed at a constant temperature of $16^{\circ}$, one at a constant temperature of $\mathbf{2 4}^{\circ}$, while the third was alternated daily between $16^{\circ}$ and $24^{\circ}$, being at the former temperature for about 16 hours, at the latter 8 hours. The light was continuous in each case. The experiment was performed four times, with the results given in table 6 . 
Table 6. The offspring of winged aphids reared, from the fourth instar, in constant temperatures of $16^{\circ}$ and $24^{\circ}$, and at alternating temperatures of $16^{\circ}$ and $24^{\circ}$

\begin{tabular}{|c|c|c|c|c|c|}
\hline \multicolumn{2}{|c|}{ Constant $16^{\circ}$} & \multicolumn{2}{|c|}{ Constant $24^{\circ}$} & \multicolumn{2}{|c|}{ Alternating $16^{\circ}$ and $24^{\circ}$} \\
\hline Parthenogenetic & Gamic & Parthenogenetic & Gamic & Parthenogenetic & Gamic \\
\hline 34 & 73 & 17 & 50 & 32 & 98 \\
\hline 4 & 81 & 5 & 26 & 3 & 77 \\
\hline 3 & 29 & 17 & 20 & 2 & 37 \\
\hline 0 & 17 & 33 & 14 & 3 & 48 \\
\hline 41 & 210 & 72 & 110 & 40 & 220 \\
\hline $16.3 \%$ & & $39.6 \%$ & & $133 \%$ & \\
\hline
\end{tabular}

High temperature again shows its capacity to induce parthenogenesis $(39.6 \%$ as against $16.3 \%$ or less $)$, while alternating high and low temperatures seem to be quite as favorable to gamic reproduction as is constant low temperature.

\section{Can Mode of Reproduction be Altered After Birth?}

In all of the experiments so far described, only the parents were subjected to differences of temperature and light. The offspring were removed, while still only one to three days old, to ordinary room conditions. The effect of these agents demonstrated by the experiments is, therefore, mostly if not exclusively a prenatal effect. This does not exclude the possibility that a similar effect is produced after birth, and that if the offspring had been subjected to the same conditions as their parents an even more striking difference would have been obtained. For any critical judgment of the processes involved in the determination of the mode of reproduction, a knowledge of the time at which it occurs is essential.

To ascertain whether a similar postnatal effect on reproduction is produced by light and temperature, numerous winged aphids in the third and fourth instars were put into constant temperature chambers at $16^{\circ}$, $22^{\circ}$, and $28^{\circ}$, respectively. At each of the temperatures, some aphids were kept in continuous light, others were alternated between light and darkness (8 hours and 16 hours, respectively). Their offspring were removed daily, hence at ages usually less than 24 hours, and those from 
each of the six lots of parents were divided into six approximately equal groups, two of which were reared at $16^{\circ}$, two at room temperature, and two at $24^{\circ}$. At each of these temperatures, one of the groups of offspring was reared in alternating light and darkness $(8$ hours and 16 hours), and one group in continuous light. The experiments were too extensive for all to be performed simultaneously with the equipment and time available, but care was taken to make the conditions as nearly as possible the same each time. Fach part of the experiment was repeated until 70 to 100 offspring had been obtained.

The nature of the offspring is shown in table 7. The offspring born in any given condition of light and temperature include about the same percentage of parthenogenetic females, regardless of the conditions under which they were reared to maturity. There are irregularities in these percentages, but they are small and contradictory in the various parts of the experiment, hence are presumably insignificant. Apparently all the influence of light and temperature upon the mode of reproduction is exerted before birth, or before an age of 24 hours after birth. How long before birth the effect is produced is not ascertained, since the parents were put into the stated conditions in the third or fourth instars, which would be 5 to 10 days before the first offspring were born.

Other information is conveyed by table 7, bearing upon the questions dealt with in table 5. High temperature $\left(28^{\circ}\right)$ is again shown to have favored parthenogenetic offspring. Even a temperature of $22^{\circ}$ induced more partenogenetic offspring than did $16^{\circ}$. For these higher temperatures, the percentages agree rather closely with those of table 5 . For $16^{\circ}$, however, the parthenogenetic offspring were much less numerous than in table 5, a fact already mentioned in the discussion of the latter table as showing that the higher percentage at $16^{\circ}$ than at $14^{\circ}, 18^{\circ}$ and $20^{\circ}$ probably did not mean that there was an exceptional effect of $16^{\circ}$ among various low temperatures. The $18.5 \%$ and $21.5 \%$ at $16^{\circ}$ in table 5 must have been owing to some other factor not controlled.

The light effects shown in table 7 are likewise in fairly close agreement with those in table 5 , except that at $16^{\circ}$ there was no excess of parthenogenesis in continuous light over that in 8-hour light. The slight excesses in continuous light at all of the low temperatures in table 5 are therefore probably not significant. At $22^{\circ}$, however, there was a consistently greater percentage of parthenogenetic offspring in continuous light, and a similarly consistent excess in continuous light at $28^{\circ}$. 
Table 7. Showing that offspring of winged parents do not change or light obtaining

\begin{tabular}{|c|c|c|c|c|c|c|c|}
\hline \multirow{3}{*}{\multicolumn{2}{|c|}{$\begin{array}{c}\text { Conditions Under } \\
\text { Which Parents Were } \\
\text { Reared }\end{array}$}} & \multicolumn{6}{|c|}{ Offspring } \\
\hline & & \multicolumn{6}{|c|}{ At $16^{\circ}$} \\
\hline & & \multicolumn{3}{|c|}{ 8-hour light } & \multicolumn{3}{|c|}{ 24-hour light } \\
\hline $\begin{array}{c}\text { Tem- } \\
\text { perature }\end{array}$ & $\begin{array}{c}\text { Light, in } \\
\text { hours daily }\end{array}$ & Parth. & Gamic & $\begin{array}{l}\text { Percent } \\
\text { parth. }\end{array}$ & Parth. & Gamic & $\begin{array}{c}\text { Percent } \\
\text { parth. }\end{array}$ \\
\hline $16^{0}$ & 8 & 4 & 59 & $6: 3$ & 5 & 62 & $7 \cdot 5$ \\
\hline $16^{\circ}$ & 24 & 3 & 64 & $4: 5$ & 1 & 59 & $1 \cdot 7$ \\
\hline $22^{\circ}$ & 8 & 7 & 79 & $8 \cdot 1$ & 6 & 75 & $7 \cdot 4$ \\
\hline $22^{\circ}$ & 24 & 10 & 69 & 127 & 11 & 76 & $12 \cdot 6$ \\
\hline $28^{\circ}$ & 8 & 51 & 22 & $69 \cdot 9$ & 56 & 20 & $73 \cdot 7$ \\
\hline $28^{\circ}$ & 24 & 55 & 15 & $78 \cdot 6$ & 54 & 17 & $76 \cdot 1$ \\
\hline
\end{tabular}

\section{Rate of Action of Temperature and Light in Modifying Reproduction}

It was shown in table 3 that after a change of temperature from $16^{\circ}$ to $24^{\circ}$, and a simultaneous change of light from alternating to continuous, about three weeks were required for the complete transition from gamic to parthenogenetic offspring. Information concerning the time required to commence this transition, and further indications of the rate at which the change takes place, were obtained in the following experiment.

Winged aphids taken from cultures at room conditions within 24 hours after birth, in January at which time winged females were producing almost exclusively gamic daugthers, were subjected to continuous light and a temperature of $24^{\circ}$ for various lengths of time ranging from 3 to 16 days, after which they were kept in alternating light and darkness ( 8 hours and 16 hours, respectively) and a temperature of $16^{\circ}$. Those kept for 3 days and 6 days at high temperature and in continuous light did not begin to reproduce until 5 to 10 days after the change to $16^{\circ}$; their entire families were reared. The lot which was kept 9 days at $24^{\circ}$ and in continuous light began to reproduce at about the time of change to $16^{\circ}$; practically the entire families of these were preserved. Those which were kept for 12 days and 16 days at $24^{\circ}$ and in continuous light began to reproduce before the change to $16^{\circ}$; their offspring produced before this change were not kept. Table 8 
Control of Gamic and Parthenogenetic Reproduction in Winged Aphids \&c. 117

their mode of reproduction in response to conditions of temperature after birth

\begin{tabular}{|c|c|c|c|c|c|c|c|c|c|c|c|}
\hline \multicolumn{12}{|c|}{ Offspring } \\
\hline \multicolumn{6}{|c|}{ At room temperature } & \multicolumn{6}{|c|}{ At $24^{\circ}$} \\
\hline \multicolumn{3}{|c|}{ 8-hour light } & \multicolumn{3}{|c|}{ 24-hour light } & \multicolumn{3}{|c|}{ 8-hour light } & \multicolumn{3}{|c|}{ 24-hour light } \\
\hline Parth. & Gamic & $\begin{array}{l}\text { Percent } \\
\text { parth. }\end{array}$ & Parth. & Gamie & $\begin{array}{l}\text { Percent } \\
\text { parth. }\end{array}$ & Parth. & Gamic & $\begin{array}{c}\text { Percent } \\
\text { parth. }\end{array}$ & Parth. & Gamic & $\begin{array}{l}\text { Percent } \\
\text { parth. }\end{array}$ \\
\hline 2 & 57 & $3 \cdot 4$ & 4 & 60 & $6 \cdot 3$ & 3 & 54 & 53 & 5 & 52 & 8.8 \\
\hline 4 & 61 & $6 \cdot 2$ & 3 & 40 & $7 \cdot 0$ & 4 & 65 & $5 \cdot 8$ & 2 & 62 & $3 \cdot 1$ \\
\hline 8 & 81 & $9 \cdot 0$ & 6 & 74 & $7 \cdot 5$ & 5 & 78 & $6 \cdot 0$ & 8 & 79 & 9.2 \\
\hline 8 & 72 & $10 \cdot 0$ & 9 & 70 & $8 \cdot 9$ & 11 & 71 & $13 * 4$ & 10 & 74 & $11 \cdot 9$ \\
\hline 48 & 15 & 762 & 58 & 20 & 744 & 56 & 19 & $74 \cdot 7$ & 52 & 20 & 719 \\
\hline 59 & 14 & $80^{\circ} 8$ & 60 & 13 & $82 \cdot 2$ & 57 & 13 & $81 \cdot 4$ & 60 & 12 & $83: 3$ \\
\hline
\end{tabular}

shows the effect of these various periods of high temperature and continuous light on the mode of reproduction in their offspring.

Only three days exposure to high temperature and continuous light had no effect, or the effect was lost by the time the aphids reached maturity and began to reproduce ten days later; all the offspring were gamic. Six days exposure produced a few parthenogenetic offspring early in the familly, but this effect disappeared within 13 days after the change to $16^{\circ}$ and alternating light and darkness. High temperature and continuous light for 9 days after birth resulted in some parthenogenetic offspring throughout the family, without any apparent tendency either to increase or decrease their numbers during the reproductive period. After 12 days exposure, most of the offspring were parthenogenetic, but the change to $16^{\circ}$ was followed by a steady return to gamic daughters. Sixteen days of high temperature and continuous light sufficed for a nearly complete transition to parthenogenesis, but about 10 days after the change to $16^{\circ}$ the offspring suddenly became mostly gamic.

The change from gamic to parthenogenetic reproduction was somewhat more rapid than in table 3 , since 18 days sufficed for the complete transition (last 3 columns of table 8) as compared with about three weeks in table 3 . Six days were enough, however, to change some daughters to the parthenogenetic type, while three days were insufficient 
Table 8. Showing the effect of varying exposures of young winged in their

\begin{tabular}{|c|c|c|c|c|c|c|}
\hline \multicolumn{7}{|c|}{ Number of Days parents Were at High } \\
\hline \multicolumn{3}{|c|}{$3 \cdot$ days } & \multicolumn{3}{|c|}{6 days } & \multirow{2}{*}{$\begin{array}{c}9 \text { days } \\
\begin{array}{c}\text { Days after } \\
\text { change } \\
\text { to } 16^{\circ}\end{array}\end{array}$} \\
\hline $\begin{array}{l}\text { Days after } \\
\text { change } \\
\text { to } 16^{\circ}\end{array}$ & $\begin{array}{l}\text { Partheno- } \\
\text { genetic }\end{array}$ & Gamic & $\begin{array}{l}\text { Days after } \\
\text { change } \\
\text { to } 16^{\circ}\end{array}$ & $\begin{array}{l}\text { Partheno- } \\
\text { genetic }\end{array}$ & Gamic & \\
\hline $9-10$ & 0 & 4 & $5-7$ & 3 & 23 & $0-1$ \\
\hline $10-12$ & 0 & 29 & $7-9$ & 3 & 20 & $1-3$ \\
\hline $12-14$ & 0 & 16 & $9-11$ & 4 & 50 & $3-4$ \\
\hline $14-16$ & 0 & 18 & $11-13$ & 4 & 27 & $4-6$ \\
\hline $16-18$ & 0 & 20 & $13-15$ & 0 & 39 & $6-8$ \\
\hline $18-20$ & 0 & 16 & $15-17$ & 0 & 36 & $8-10$ \\
\hline $20-22$ & 0 & 10 & $17-19$ & 0 & 6 & $10-12$ \\
\hline $22-24$ & 0 & 7 & $19-21$ & 0 & 14 & $12-14$ \\
\hline \multirow[t]{4}{*}{$24-27$} & 0 & 4 & $21-24$ & 0 & 8 & $14-16$ \\
\hline & & & $24-36$ & 0 & 2 & $16-18$ \\
\hline & & & & & & $18-21$ \\
\hline & & & & & & $21-27$ \\
\hline
\end{tabular}

for any change, at least when these three days were the first three days after birth. The entire detectible change took place, therefore, between about the fourth or fifth day and the 18th day after high temperatare began, or over a period of about two weeks.

The return to gamic daughters after the change to $16^{\circ}$ and alternating light and darkness was perhaps sligthly more rapid than the change from gamic to parthenogenetic, since 13 days sufficed for complete change in this direction after only 6 days of high temperature, while 10 days effected practically a complete change to gamic daughters after 16 days of high temperature.

Further evidence of the effect of temperatare was incidentally obtained in other experiments designed to ascertain the mechanism of the transformation of one type of female into the other. This study of the mechanism is merely in progress, and the experiments are not being reported in this paper in relation to their primary object. However, they show in miscellaneous ways the same striking effect of temperature as is manifest in table 8 , and certain additional features which may be of significance. They are described here, therefore, in so far as they bear on the mere fact of modification by temperature. 
Control of Gamic and Parthenogenetic Reproduction in Winged Aphids \&c. 119

aphids to high temperature and continuous light upon reproduction offspring

\begin{tabular}{|c|c|c|c|c|c|c|c|}
\hline \multicolumn{8}{|c|}{ Temperature and Continuous Light } \\
\hline \multicolumn{2}{|c|}{9 days } & \multicolumn{3}{|c|}{12 days } & \multicolumn{3}{|c|}{16 days } \\
\hline $\begin{array}{l}\text { Partheno- } \\
\text { genetic }\end{array}$ & Gamic & $\begin{array}{c}\text { Days after } \\
\text { change } \\
\text { to } 16^{\circ}\end{array}$ & $\begin{array}{c}\text { Partheno- } \\
\text { genetic }\end{array}$ & Gamic & $\begin{array}{c}\text { Days after } \\
\text { change } \\
\text { to } \mathbf{1 6}^{\mathbf{0}}\end{array}$ & $\begin{array}{l}\text { Partheno- } \\
\text { genetic }\end{array}$ & Gamic \\
\hline 3 & 5 & $0-2$ & 13 & 2 & $0-2$ & 34 & 1 \\
\hline 7 & 16 & $2-4$ & 11 & 7 & $2-4$ & 26 & 0 \\
\hline 5 & 28 & $4-6$ & 8 & 9 & $4-6$ & 16 & 0 \\
\hline 0 & 40 & $6-8$ & 5 & 12 & $6-8$ & 11 & 0 \\
\hline 5 & 30 & $8-10$ & 7 & 17 & $8-10$ & 16 & 2 \\
\hline 3 & 27 & $10-12$ & 2 & 5 & $10-13$ & 1 & 8 \\
\hline 5 & 23 & $12-14$ & 3 & 13 & $13-25$ & 1 & 3 \\
\hline 3 & 23 & $14-17$ & 4 & 18 & & & \\
\hline 2 & 7 & $17-29$ & 2 & 5 & & & \\
\hline 3 & 11 & & & & & & \\
\hline 2 & 18 & & & & & & \\
\hline 2 & 16 & & & & & & \\
\hline
\end{tabular}

In these miscellaneous experiments temperature was the only factor involved; continuous light was employed in all of them. Six of these experiments are grouped together in table 9. The winged aphids used as parents were collected daily, each lot within 24 hours after birth, from March 11-14, and immediately put at the temperature indicated at the head of the appropriate section of table 9. Their offspring were reared to maturity at room temperature. From the dates in the table the approximate age of the parents at any given point of the experiment can be ascertained.

Sections 1 and 2 of iable 9 show again that alternating low and high temperatures were about as favorable to gamic daughters as was constant low temperature. This agrees closely with table 6 . Sections 3 and 4 show that 3 days of high temperature had little effect, while 6 days of high temperature produced numerons parthenogenetic offspring scattered over a long period without any obvious tendency either to increase or decrease in numbers during that time. This latter result is very similar to the effect of 9 days high temperature in table 8 , indicating that the effect of high temperature was more quickly produced in March than it was in January. In sections 5 and 6 , an initial period 
Table 9. The effect of temperature, variously applied to winged aphids beginning within 24 hours after birth, upon the mode of reproduction in their offspring. The duration and changes of temperature are separately indicated in the six sections of the table

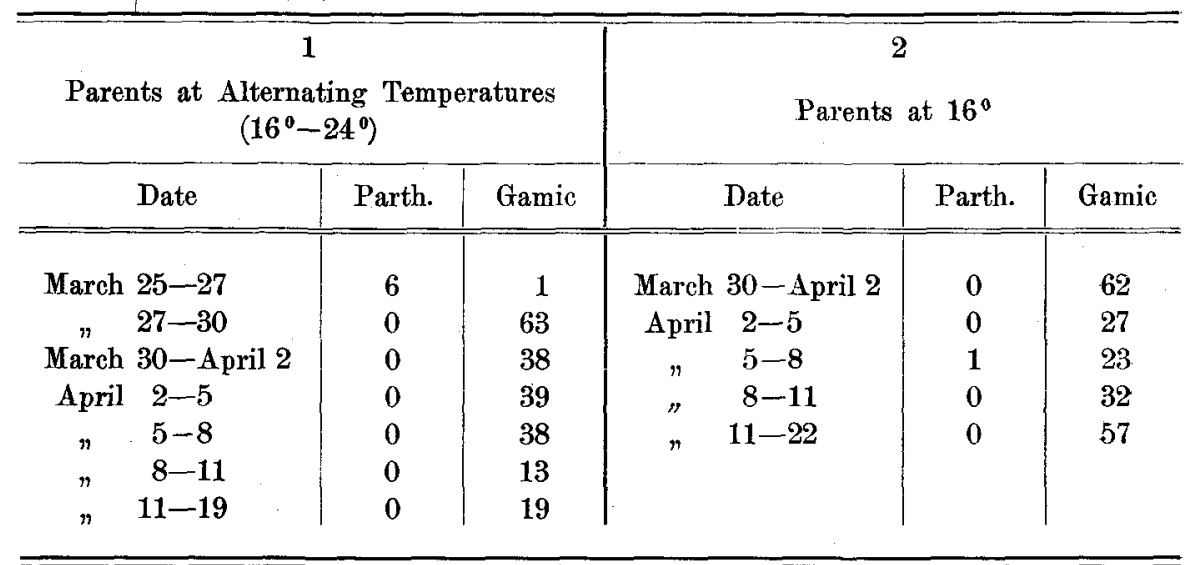

\begin{tabular}{|c|c|c|c|c|c|}
\hline \multicolumn{3}{|c|}{$\begin{array}{c}3 \\
\text { Parents at } 24^{\circ} \text { for } 3 \text { Days, Thereafter } \\
\text { at } 16^{\circ}\end{array}$} & \multicolumn{3}{|c|}{$\begin{array}{c}4 \\
\text { Parents at } 24^{\circ} \text { for } 6 \text { Days, Thereafter } \\
\text { at } 16^{\circ}\end{array}$} \\
\hline Date & Parth. & Gamic & Date & Parth. & Gamic \\
\hline March 28-30 & 1 & 53 & March 28-30 & 12 & 20 \\
\hline March $30-$ April 1 & 0 & 26 & March 30-April 1 & 11 & 31 \\
\hline April $1-2$ & 1 & 33 & April 1-3 & 6 & 38 \\
\hline $2-4$ & 0 & 38 & $3-5$ & 4 & 22 \\
\hline $4-5$ & $\mathbf{0}$ & 30 & $5-8$ & 14 & 58 \\
\hline $5-7$ & 0 & 42 & $8-11$ & 3 & 39 \\
\hline $7-8$ & 0 & 54 & $11-15$ & 9 & 57 \\
\hline $8-11$ & 0 & 97 & $15-22$ & 28 & 56 \\
\hline$\Rightarrow \quad 11-15$ & $\mathbf{0}$ & 69 & April 22-May 1 & 1 & 0 \\
\hline$n \quad 15-22$ & 0 & 29 & & & \\
\hline
\end{tabular}

\begin{tabular}{c|c|c|c|c|c}
\hline \multicolumn{2}{c|}{5} & \multicolumn{4}{|c}{6} \\
$\begin{array}{c}\text { Parents at Alternating Temperatures } \\
\left(\mathbf{1 6}^{\circ}-2^{\circ}\right) \text { for 15 days, Thereafter at } 24^{\circ}\end{array}$ & Parents at $16^{\circ}$ for 14 Days, Thereafter \\
at $24^{\circ}$
\end{tabular}


of about two weeks at low or alternating low and high temperatures made the first offspring practically all gamic. A change to high temperature early in the reproductive period was followed by a rapid change to the production of parthenogenetic daughters, a change which was completed in about a week in section 5, but had not reached completion in the same time in section 6 . This is considerahly less time than was required for the similar change in table 8 , representing aphids experimented on in January.

A more direct test of the effect of changing from high to low temperature is found in the following experiment. Beginning April 27, numerous winged aphids, within three days after birth, were divided into two groups, one kept in alternating temperatures $\left(16^{\circ}-24^{\circ}\right)$, the other kept at $24^{\circ}$ until May 5 , then changed to alternating temperatures $\left(16^{\circ}-24^{\circ}\right)$. The latter group began reproducing May 3 , their first offspring being produced at the high temperature. Table 10 gives the results. Eight days of high temperature sufficed to make the offspring exclusively parthenogenetic, an effect which continued for 7 days after the parents were changed to alternating temperatures. After that change, the offspring became gradually more and more gamic, though they were not exclusively gamic by June 7 , when the experiment was discontinued.

By the collective experiments described in this section it is demonstrated that winged parents may be made to change from

Table 10. Showing the change from parthenogenetic to gamic daughters as a result of changing winged parents from high to alternating high and low temperatures (right half of table)

\begin{tabular}{|c|c|c|c|c|c|c|c|c|c|}
\hline & \multirow{2}{*}{ Date } & \multirow{2}{*}{$\begin{array}{l}\text { Tempe- } \\
\text { rature } \\
\text { in De- } \\
\text { grees } \\
\text { C. }\end{array}$} & \multicolumn{2}{|c|}{ Offspring } & \multirow{2}{*}{\multicolumn{2}{|c|}{ Date }} & \multirow{2}{*}{$\begin{array}{c}\text { Tempe- } \\
\text { rature } \\
\text { in De-- } \\
\text { grees } \\
\text { C. }\end{array}$} & \multicolumn{2}{|c|}{ Offspring } \\
\hline & & & Parth. & Gamie & & & & Parth. & Gamic \\
\hline April & 27-May 7 & $16-24$ & 1 & 9 & April & 27-May 3 & 24 & 0 & 0 \\
\hline May & $7-11$ & $16-24$ & 1 & 17 & May & $3-5$ & 24 & 11 & 1 \\
\hline$n$ & $11-16$ & $16-24$ & 0 & 20 & $\eta$ & $5-8$ & $16-24$ & 10 & 0 \\
\hline$"$ & $16-21$ & $16-24$ & 0 & 26 & $"$ & $8-12$ & $16-24$ & 39 & 0 \\
\hline$n$ & $21-26$ & $16-24$ & 0 & 19 & $"$ & $12-17$ & $16-24$ & 27 & 6 \\
\hline$n$ & $26-31$ & $16-24$ & 0 & 22 & " & $17--22$ & $16-24$ & 30 & 31 \\
\hline May & 31--June 6 & $16-24$ & 0 & 24 & $\eta$ & $22-26$ & $16-24$ & 6 & 10 \\
\hline June & $6-10$ & $16-24$ & 0 & 11 & May & 26 -June 1 & $16-24$ & 7 & 20 \\
\hline & & & & & June & $1-7$ & $16-24$ & 4 & 17 \\
\hline
\end{tabular}


the production of only or mostly gamic daughters to the production of only parthenogenetic daughters, by the application of high temperatures for times varying from 1 week (in late spring) to 3 weeks (in winter). The difference between the time required in January and and that required in May is probably due to a change which the aphids undergo in response to natural temperatures. By May, much of the physiological change due to high temperature has taken place, even though winged aphids are at that time still producing mostly gamic danghters. The change from parthenogenetic to gamic daughters is likewise demonstrated, although, from the circumstance that the experiments were performed in winter the tests in that direction were less numerous. None of these latter tests includes the whole change from exclusively parthenogenetic to exclusively gamic daughters. The nearest approaches to such complete change are found in tables 8 and 10. The dates in these tables suggest that it takes longer to change from parthenogenetic to gamic than from gamic to parthenogenetic.

\section{Rate of Postnatal Development Influenced by Prenatal Light and Temperature}

Casual observation indicated that aphids whose parents were raised in various conditions of light and temperature were growing and differentiating at different rates. A fairly accurate measure of the difference in these rates of development was obtained in the following manner. Six groups of winged aphids, all from the same source and in the fourth instar, were taken from room conditions of light and temperature, in which winged aphids were at that time (early in May) producing mostly gamic daughters, and put at $16^{\circ}, 22^{\circ}$, and $28^{\circ}$. In each of these temperatures one group was kept in alternating light and darkness ( 8 hours and 16 hours, respectively), another group in continuous light. When they began to reproduce the parents were removed to a new plant each day, and the offspring (all under 24 hours of age) were brought to room conditions. As the offspring became nearly mature they were carefully examined every day and those which had become adult were removed and recorded. The average age at maturity was thus ascertained for the offspring of each group. These ages are given in table 11. 
Control of Gamic and Parthenogenetic Reproduction in Winged Aphids \&c. 123

Table 11. Showing that the rate of postnatal development of aphids is modified by the prenatal conditions of light and temperature

\begin{tabular}{|c|c|c|c|c|c|}
\hline \multirow{2}{*}{\multicolumn{2}{|c|}{$\begin{array}{l}\text { Conditions Under Which } \\
\text { Parents Were Reared }\end{array}$}} & \multicolumn{4}{|c|}{ Offspring } \\
\hline & & \multicolumn{2}{|c|}{ Parthenogenetic } & \multicolumn{2}{|c|}{ Gamic } \\
\hline $\begin{array}{l}\text { Temperature } \\
\text { in degrees } \mathrm{C} .\end{array}$ & $\begin{array}{l}\text { Hours of } \\
\text { light, daily }\end{array}$ & Number & $\begin{array}{l}\text { Mean age, } \\
\text { in days }\end{array}$ & Number & $\begin{array}{c}\text { Mean age, } \\
\text { in days }\end{array}$ \\
\hline 16 & 8 & 5 & $8 \cdot 8+0.45$ & 31 & $8 \cdot 8 \pm 0 \cdot 18$ \\
\hline 16 & 24 & $\left.0^{1}\right)$ & - & 46 & $11 \cdot 8 \pm 0 \cdot 18$ \\
\hline 22 & 8 & 5 & $8 \cdot 4+0 \cdot 70$ & 18 & $9.7 \pm 0.33$ \\
\hline 22 & 24 & 9 & $12 \cdot 0 \pm 0 \cdot 91$ & 79 & $12 \cdot 4 \pm 0 \cdot 08$ \\
\hline 28 & 8 & 69 & $8 \cdot 7 \pm 0 \cdot 18$ & 23 & $9 \cdot 6 \pm 0 \cdot 27$ \\
\hline 28 & 34 & 59 & $8 \cdot 0+0 \cdot 10$ & 1 & $8 \cdot 0$ \\
\hline
\end{tabular}

At $16^{\circ}$ and $22^{\circ}$, continuous light applied to the parents plainly retards the rate of development of the offspring, as compared with alternating light and darkness applied to the parents. This is true of parthenogenetic offspring as well as of gamic, though it is a little less certain of the former owing to the small number of parthenogenetic offspring produced at these temperatures. At $28^{\circ}$, however, continuous light applied to the parents probably hastens the postnatal development of the offspring as compared with 8-hour light. The differences in the latter comparison are small, but that relating to parthenogenetic offspring (8.0 as compared with 8.7 days) appears to be statistically significant. The gamic offspring at $28^{\circ}$ yield less certain results since only one was produced in continuous light.

These differences in the rate of development after birth, being due solely to influences acting before birth, are of some importance in arriving at a physiological explanation of the action of light and temperature. As is shown in this paper, continuous light and high temperature induce the production of parthenogenetic offspring, alternating light and darkness and low temperature favor gamic offspring. Postnatal development is most rapid when light and temperature act in the same direction; it is retarded when they are opposed to one another. It is apparent that rate of postnatal development is dependent upon the

i) It is presumably purely accidental that no parthenogenetic offspring were produced at $16^{\circ}$ and in continuous light. (See table 4 and the accompanying discussion.) 
progress made before birth in processes that are influenced by both temperature and light. If temperature and light affect these processes in the same way, their progress may be assumed to be considerable. If temperature and light antagonize one another, the progress should be less.

It is perhaps idle to speculate upon the nature of these processes, whether there is only one change which takes place in a plus and a minus direction, or whether there are wholly distinct processes each of which neutralizes the developmental effect of the other. There is nothing to indicate whether the processes determining the rate of development are identical with those differentiating gamic from parthenogenetic females, or whether these things are wholly distinct. It would be possible to bring these things all under a single point of view by assuming that parthenogenetic and gamic females are determined by high and low quantities of some substance, and that postnatal development is rapid if the quantity is relatively either very large or very small, but is slow in the presence of an intermediate quantity. There is, however, no evidence for such an explanation.

\section{Intermediates}

In the transformation of gamic into parthenogenetic, or parthenogenetic into gamic aphids, intermediates are produced. It is not my intention to discuss these at present. They are being studied and will receive attention in a later paper. Mention of them is made here merely to point out that in all the foregoing experiments, aphids have been adjudged parthenogenetic or gamic purely from the nature of their reproductive systems. Secondary characters have been ignored. Individuals in which the reproductive systems were so seriously mixed that they did not clearly belong to either type were omitted. They were not very numerous, and including them would not alter the conclusions reached.

\section{Summary}

High temperatures $\left(24^{\circ}\right.$ or above), applied to winged aphids of the species used, tended to make the offspring of those aphids parthenogenetic females. Low temperatures $\left(16^{\circ}\right.$ or below) tended to make the offspring gamic females. 
Continuous light applied to winged aphids tended to make their offspring parthenogenetic; alternating light and darkness tended to make them gamic. The effectiveness of light varied with the temperature. Thus, at $16^{\circ}$, there was practically no difference between continuous light and alternating light and darkness; but at $22^{\circ}$ to $28^{\circ}$ the continuous light was distinctly favorable to parthenogenetic offspring. Light was much less effective, however, than temperature,

Alternating high and low temperatures $\left(16^{\circ}\right.$ for 16 hours, $24^{\circ}$ for 8 hours daily) was at least as favorable to gamic offspring as was constant low temperature.

The mode of reproduction was found to be decided for any individual before birth. Light and ternperature did not change it thereafter.

To change completely from the production of gamic daughters to the production of parthenogenetic daughters required from one week (May and June) to three weeks (January), The seasonal difference was probably due to the temperatures prevailing, part of the temperature effect having been produced before the experiment began in May.

High temperatures applied to winged parents immediately after birth, for periods varying from 6 days to 16 days, produced parthenogenetic offspring in increasing numbers with increasing duration of high temperature. These numbers were in general larger in March than in January. High temperature for only 3 days after birth had no effect on the nature of the offspring.

A nearly complete change from parthenogenetic to gamic offspring, by rearing the winged parents at low temperature much or all of the time, was effected in about 5 weeks (in May and June).

Aphids whose prenatal development took place under conditions of light which favored parthenogenetic reproduction, and conditions of temperature which favored gamic reproduction, underwent their postnatal development more slowly than did aphids whose prenatal development occurred in light and temperature both of which acted in the same direction. When the light during prenatal development favored gamic reproduction, and the temperature favored parthenogenetic, the retardation of postnatal development was small but probably significant.

A possible explanation for both the determination of the two types of individual and the rate of development would be that a large or small quantity of some substance differentiates parthenogenetic and gamic females, and that development is rapid only when this quantity is distinctly high or low, but slow when the quantity is intermediate. 
126 Shull, Control of Gamic and Parthenogenetic Reproduction in Winged Aphids \&c.

\section{Literature Cited}

AcKerman, L., 1926. The physiological basis of wing production in the grain aphid. Journ. Exp. Zool., 44, p. 161.

SHuLl, A. F., 1928. Duration of light and the wings of the aphid Macrosiphum solanifolii. W. Roux' Arch. Entwickl. d. Org., 113, S. 210-239.

-, 1929a. Determination of types of individnals in aphids, rotifers and cladocera. Biol. Reviews, 4, p. 218-248.

-, 1929b. Effect of intensity and duration of light and of duration of darkness, partly modified by temperature, upon wing-production in aphids. W. Roux' Arch. Entwickl. d. Org., 115, S. 825-851. 